\title{
Transnationale etnische handel in de Brabantstraat
}

AUTEUR Tim Cassiers

FOTOGRAFIE Tim Cassiers

Etnische gemeenschappen worden vaak vastgepind op bepaalde buurten. Hun lokale inbedding, gelinkt aan segregatie- en ander processen is een veel bestudeerd en besproken fenomeen. Maar achter deze lokale inbedding ontspint zich ook een andere ruimtelijke dimensie, namelijk één van de transnationale netwerken.

Eén van de facetten van deze overstijgende ruimte is de transnationale etnische handel. Deze is er op gericht om goederen en diensten op een vlotte manier te laten circuleren tussen al deze plaatsen en gemeenschappen. De Brabantstraat in Brussel is een knooppunt in een dergelijk handelsnetwerk. Hoewel het handelsapparaat van de Brabantstraat stevig is ingebed in haar overwegend Turkse omgeving, overstijgt haar uitstraling en belang dit lokale. Niet alleen trekt ze klanten aan van ver buiten Brussel en zelfs uit naburige landen, haar import/export handelsnetwerk vertakt zich bovendien over heel Europa tot in de Maghreb en het Nabije, Verre en Midden-Oosten. Het linken van vele van zulke handelsnetwerken brengt een ander soort mondialisering op gang; niet één die uitgaat van de grote multinationals of van de grote internationale organisaties, maar één die steunt op een savoir-circuler van duizenden kleine en grotere ondernemers.

\section{Etnisch ondernemerschap}

De aanwezigheid van etnische minderheden in onze steden ligt aan de basis van etnisch ondernemerschap. Deze minderheden concentreren zich vaak in bepaalde wijken, waardoor de associatie tussen een gemeenschap en een bepaald stadsdeel welhaast automatisch gemaakt wordt in de hoofden van mensen. Dit uit zich in namen als Klein-Istanbul, Chinatown of Matonge. Een concentratie van etnische groepen wordt soms als problematisch gezien, vooral dan in het licht van integratie. Maar evengoed biedt ze kansen voor ondernemende personen uit de gemeenschap om een eigen handelszaak te beginnen die zich richt op deze gemeenschap. Ze vinden in etnische buurten een marktsituatie die hen toelaat om op deze manier inkomsten te verwerven.

We spreken van etnisch ondernemerschap als de ondernemer op de één of andere manier voordeel put uit zijn etniciteit bij het uitoefenen van zijn activiteit. Dat voordeel kan zowel liggen in de markt waarop hij zich richt, als in de producten die hij aanbiedt. Indien beiden etnisch van aard zijn, situeert het ondernemerschap zich in de etnische niche (zie tabel 1). De handel is er op gericht te voorzien in producten en diensten die de gemeenschap hier moet toelaten levensstijlen en gewoonten van thuis te (her)beleven. De handelaar is ingebed in de gemeenschap, hij speelt in op een vraag naar bijvoorbeeld traditionele kleding of specifieke voedingswaren (bijvoorbeeld halal) en zijn klanten maken bijgevolg ook bijna uitsluitend deel uit van de eigen gemeenschap. Dit is het archetype van etnisch ondernemen.

Deze markt is echter vrij beperkt, waardoor sommige ondernemers overschakelen naar producten en diensten die niet meer etnisch van aard zijn, maar wel inspelen op noden van de gemeenschap. Nog steeds richt de ondernemer zich nagenoeg uitsluitend op de eigen gemeenschap, waardoor hij kan profiteren van de vertrouwensband en zijn kennis van gewoonten en omgangsvormen. Hierdoor beschermt de inbedding in de gemeenschap hem tegen de concurrentie van bijvoorbeeld autochtone ondernemers in dezelfde sector. We spreken daarom van afscherming.

Toch blijft de ondernemer kwetsbaar wanneer hij zich uitsluitend op de eigen gemeenschap richt. Doorgaans bezit deze immers weinig koopkracht. Bovendien laat inbedding in de gemeenschap niet toe om al te veel winst te maken op de rug van die gemeenschap. Om betere overlevingskansen te hebben, kunnen ondernemers ook meer kapitaalkrachtige klanten uit de onthaalmaatschappij trachten aan te trekken. Eén mogelijkheid hiertoe is exotisme. De handelaar biedt hier nog steeds producten en diensten aan die uit de eigen gemeenschap komen, maar speelt hierbij in op een hang naar het vreemde en onbekende door mensen uit de onthaalmaatschappij. De restaurantbusiness is hier een typisch voorbeeld van. 


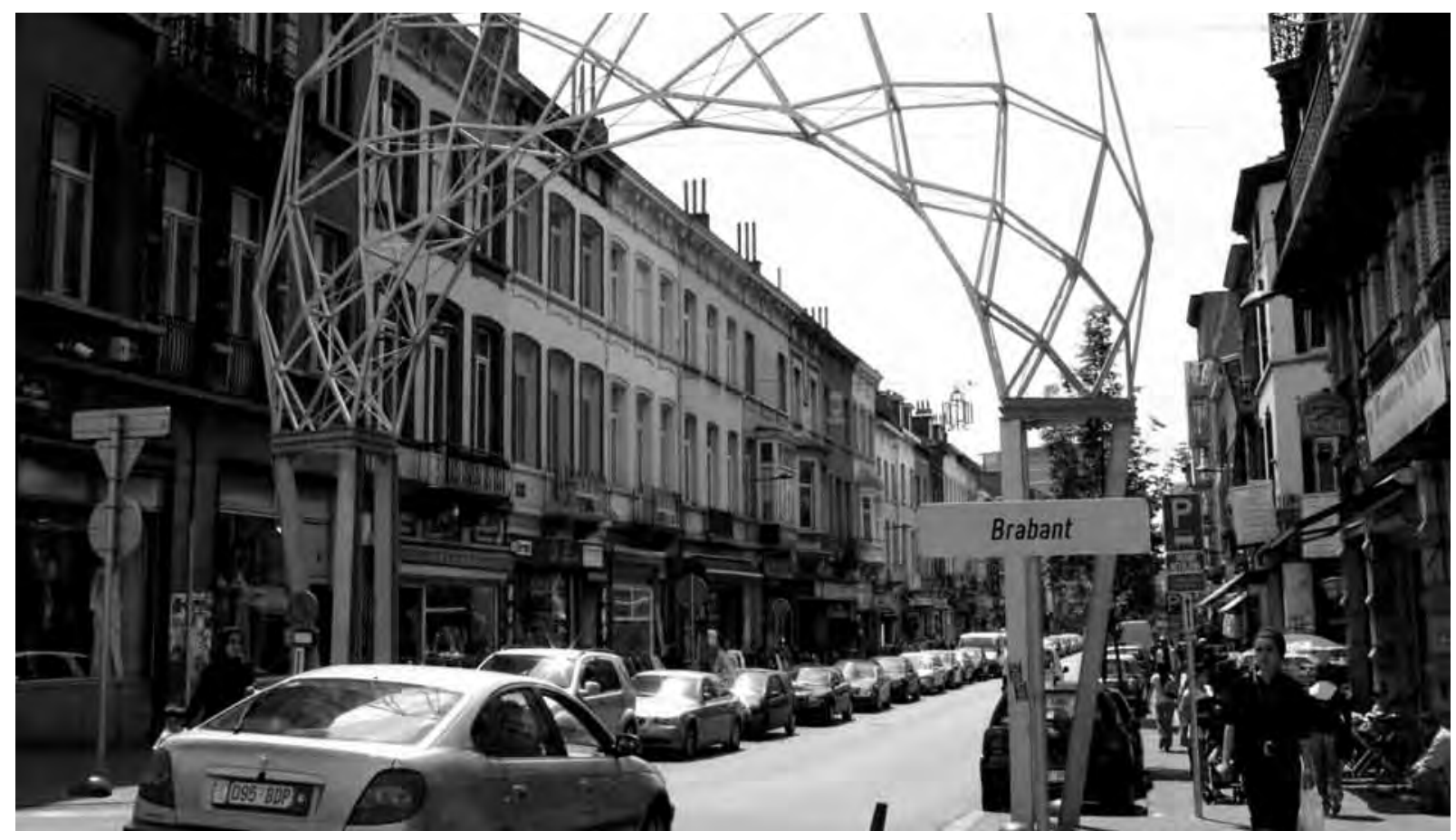

Tot slot kan de ondernemer zich volledig assimileren, waarbij noch zijn markt, noch zijn producten enige referentie naar etniciteit bezitten. In dit geval kunnen we bezwaarlijk nog spreken van etnisch ondernemerschap, aangezien de ondernemer geen direct voordeel meer haalt uit zijn achtergrond.

\begin{tabular}{|l|l|l|}
\hline Aanzet tot ondernemen & Orientatie \\
\cline { 2 - 3 } & $\begin{array}{l}\text { Naar de etnische } \\
\text { groep }\end{array}$ & $\begin{array}{l}\text { Naar de } \\
\text { onthaalmaatschappij }\end{array}$ \\
\hline Vanuit etnische groep & Etnische niche & Exotisme \\
\hline $\begin{array}{l}\text { Vanuit de onthaal- } \\
\text { maatschappij }\end{array}$ & Afscherming & $\begin{array}{l}\text { Economische } \\
\text { assimilatie }\end{array}$ \\
\hline
\end{tabular}

Tabel 1 Verschillende types van etnisch ondernemerschap

(Bron: Kesteloot en Mistiaen, 1997)

Etnisch ondernemerschap duikt regelmatig op in het maatschappelijk debat. Hierbij gaat vooral aandacht naar de etnische economie als een economische hefboom voor allochtone groepen enerzijds, en naar de integratieve kracht van etnisch ondernemerschap anderzijds. Sommigen zien het traject dat de ondernemers afleggen als een stap naar een verregaande integratie in onze maatschappij. De evolutie van etnische niche of afscherming naar exotisme of economische assimilatie wordt hierbij voorgesteld als een welhaast natuurlijk proces. Anderen benadrukken dan weer de emancipatorische kracht van etnisch ondernemerschap, niet alleen voor de handelaar zelf, maar voor de hele gemeenschap.

\section{Mondialisering van onderuit}

Het publiek debat schenkt echter veel minder aandacht aan de transnationale dimensie van etnisch ondernemen. Toch lijkt deze dimensie in het licht van de huidige mondialiseringsprocessen in toenemende mate belangrijk te worden. Dat is niet los te zien van de huidige organisatie van de markteconomie. Deze wordt gekenmerkt door een verregaande flexibilisering en mondialisering, waarbij personen, bedrijven, goederen, kapitaal, maar ook informatie en diensten zich steeds meer en steeds vrijer over de grenzen heen verplaatsen. Dit geeft aanleiding tot een geografische competitie waarbij elke stad of regio zich moet positioneren om bedrijven, personen, kapitaal... naar zich toe te trekken. Steden lijken in dit economisch organisatiemodel bevoordeeld te zijn omdat ze van oudsher concentratiepunten zijn van private en publieke macht. Omdat deze competitie mondiaal wordt gevoerd, worden steden autonomer ten opzichte van de natiestaat. Ze ageren meer en meer op mondiale schaal, stellen zich attractief op voor kapitaal en bedrijven

\section{Het import/export handels- netwerk van de Brabants- traat vertakt zich over heel Europa tot in de Maghreb en het Nabije, Verre en Midden- Oosten.}

en voor de groeiende transnationale elite.

Anderzijds vindt mondialisering echter ook van onderuit plaats. Dit idee kreeg voor het eerst vorm in het verzet tegen de mondialisering van kapitaal en bedrijven en werd vooral gelinkt aan de anti- of andersglobalisten uit de civiele maatschappij. Het pleidooi voor deze vorm van mondialisering van onderuit steunt hoofdzakelijk op de vaststelling dat de kapitalistische markteconomie mondiaal is geworden, en dat zodoende het verzet hiertegen ook een mondiale dimensie dient te krijgen.

Later duikt de term meer en meer op ter beschrijving van etnische gemeenschappen en de daarmee geassocieerde transnationale processen en fenomenen. Meer nog dan het mondiale verzet tegen de markteco- 
nomie, is deze mondialisering van onderuit inherent aan het economisch accumulatieregime. Migratie is immers één van de mechanismen die ervoor zorgen dat goedkope arbeiders naar onze steden komen. Het gaat in de huidige mondiale economische context echter niet langer op om de migrantengemeenschappen enkel te beschouwen in functie van push- en pullfactoren tussen land van oorsprong en gastland. Deze migranten opereren eveneens in een transnationale ruimte die verbindingen legt tussen de vele migrantensteden over de hele wereld. Evenmin kan men etnisch ondernemerschap enkel nog beschouwen als een brugfunctie tussen land van herkomst en de de gemeenschap hier. Ook deze is steeds meer verweven met de transnationale ruimte waarbij de handelaar sociale en culturele banden kan aanwenden om aan informatie te komen, om klanten te werven of als tussenpersonen voor de zaak. Dit netwerk vertakt zich over heel Europa, tot de Maghreb en Klein-Azië en heeft haar knooppunten in de migranten- en handelswijken ginder en hier, zoals Belsunce in Marseille, La Goutte d'Or in Parijs, Southall in Londen of de Brabantstraat in Brussel.

\section{Souk Brabant}

De Brabantwijk in Schaarbeek ligt net ten noorden van het centrum van Brussel, in de 19de eeuwse stadsuitbreidingsgordel. Het is één van die plaatsen met een grote concentratie aan allochtonen. Meer dan $80 \%$ van de bevolking is er van vreemde origine, in hoofdzaak Turken en Marokkanen. Centraal in deze buurt ligt de etnische winkelstraat Brabantstraat. In het weekend biedt de Brabantstraat in Brussel de gezellige aanblik van een souk. Mensen murwen zich door de overvolle winkelstraat, ze keuren en ze kopen. Uit cd-winkels schallen Turkse lyrics op een crossover van Arabische pop en Halk de straat in. Mensen groeten en kletsen, discussiëren in één van de vele snackbars die de straat rijk is. Auto's schuiven stapvoets aan en wringen zich op het andere rijvak wanneer ze de zoveelste dubbelgeparkeerde koper of leverancier voorbij moeten. Het verkeer stokt, de gemoederen raken meer dan eens oververhit.

\section{De etnische handelaar kan sociale en culturele banden aanwenden om aan infor- matie te komen, klanten te werven of als tussenpersonen voor de zaak.}

\footnotetext{
Deze souk wordt echter niet enkel bezocht door lokale mensen. Mensen komen uit Nederland, Frankrijk, Duitsland en zelfs uit Scandinavië om te winkelen in de Brabantstraat. Op Nederlandse en Franse blogs wordt de straat druk becommentarieerd. Waar moet je voor wat zijn? Welke snacks zijn de beste? Hoe kom je er? ... Deze chatsessies zijn de jonge en moderne variant van wat men vroeger de Arabische telefoon noemde: het woord dat van mond tot mond ging en de Brabantstraat bekendheid verschafte in alle hoeken van West-Europa. Het kenmerkt eveneens het transnationalisme waarin de straat is ingebed. Etnische
}

gemeenschappen verbinden vanuit hun origine en gemeenschappelijke migratie-ervaring verschillende lokaliteiten in Europa, onderling maar ook met de landen van oorsprong. Gebaseerd op sociaal en cultureel kapitaal construeerden zich transnationale netwerken over staatsgrenzen en andere formele belemmeringen heen.

In deze mondialisering van onderuit gedijt etnisch ondernemerschap goed. De handelaar kan gebruik maken van dit netwerk om zijn goederen en diensten aan te leveren, maar evengoed om informatie te verkrijgen en zijn afzet te verzekeren. Op die manier krijgt de etnische niche en de afgeschermde markt een andere ruimtelijke dimensie. Volgens Tarrius en Missaoui ontstaat een etnisch handelsapparaat dat tot doel heeft om goederen en diensten snel en goedkoop tussen verschillende gastlanden en landen van oorsprong te laten circuleren. Zo werd etnisch ondernemerschap tot één van de dynamieken achter transnationalisme aangezien het de gemeenschap voorziet in goederen en diensten.

De Brabantstraat heeft in dit handelsnetwerk een centrale plaats ingenomen, als één van de draaischijven voor West-Europa. De basis van dit succes is de verkoop van tapijt. Synthetisch tapijt, geproduceerd in België maar met oriëntaalse patronen, wordt in de Brabantstraat aan de man gebracht en heeft bekendheid verworven in de hele transnationale ruimte. Vertrekkende uit de Brabantstraat wordt het verhandeld over heel Europa, zelfs tot in de Maghreb. Het lokt klanten van overal naar de Brabantstraat, waar ook de rest van de winkeliers van profiteren. De concentratie aan etnische shops vormt bovendien een bijkomende troef voor de Brabantstraat. De atmosfeer van de Souk vormt een aantrekkingskracht op zich, los van tapijt of enig ander specifiek product. Het maakt de Brabantstraat tot een jaarlijks uitje voor Marokkanen uit Nederland of Algerijnen uit Frankrijk.

\section{Besluit}

Etnisch ondernemerschap vormt bij uitstek de schakel tussen Home/ Away. Het voorziet in de eerste plaats lokale etnische gemeenschappen in producten en diensten die zij nodig hebben om hun levenswijze van "thuis" aan te houden. Wanneer dit ondernemerschap het lokale overstijgt en een uitgesproken transnationale dimensie krijgt, vervaagt de grens tussen Home/Away nog meer. Etnisch ondernemerschap vormt op dat moment mee de spil tussen de lokale etnische gemeenschap, het land van oorsprong, maar evengoed andere etnische buurten over heel Europa. Precies in dit handelsapparaat kon de Brabantstraat uitgroeien tot een speler op transnationaal niveau, die tijdens het weekend mensen van overal in Europa lokt. Dit gebeurt zonder een uitgekiende marketingstrategie en wordt niet gestuurd vanuit internationaal opererende bedrijven. Integendeel, de Brabantstraat is gegroeid en groot geworden vanuit een mondialisering van onderuit, gestuurd door de stedelijke migrantengemeenschappen en hun etnische handelsnetwerken.

Daarmee zijn exotisme of economische assimilatie niet langer de enige uitweg van de etnisch ondernemer indien hij zijn markt wil uitbreiden. In de transnationale ruimte vindt hij een markt die veel groter is dan de lokale gemeenschap. Het biedt hem de mogelijkheid om binnen de etnische niche of de afgeschermde markt een zaak uit te bouwen die gebruik maakt van het savoir-circuler van duizenden kleine ondernemers. 


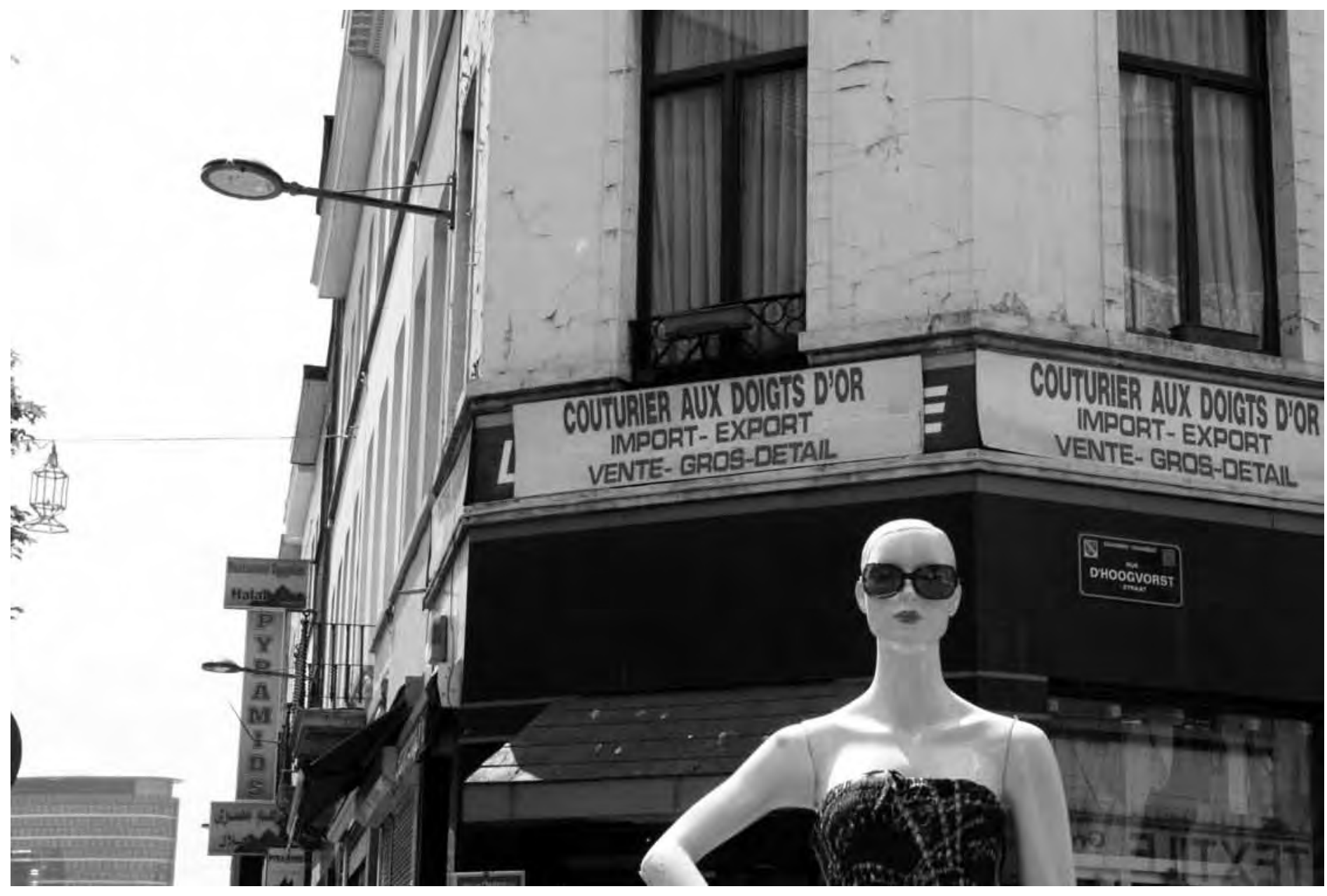

Is etnisch ondernemerschap dan nog een weg naar integratie? Dat is het zeker, niet indien we integratie als assimilatie aan het lokale territorium beschouwen, maar eerder als een emancipatorische beweging. Deze kan zich evenmin beperken tot het lokale niveau, maar moet zich enten op een complexe geografie van wisselwerkingen tussen ruimte, territorium, netwerken en schaal, die deze mondialisering van onderuit ten volle in rekening brengt.

Tim Cassiers (tim.cassiers@ees.kuleuven.be) is onderzoeker verbonden aan het departement Aard- en omgevingswetenschappen van de Katholieke Universiteit Leuven en aan de onderzoeksgroep Cosmopolis van de Vrije Universiteit Brussel. Hij is als stadsgeograaf vooral bezig met Brussel. Zijn interesse gaat hierbij uit naar etnisch ondernemerschap als factor van sociale innovatie. Daarnaast doet hij ook onderzoek naar governance in Belgische steden.

Literatuurselectie

Atrium (2007), Barometer van Brusselse handelswijken, Brussel: Atrium Cassiers, T. (1999) Etnisch ondernemen in de transnationale ruimte: De Brabantstraat in Brussel, onuitgegeven licentiaatsverhandeling, K.U.Leuven Falk, R. (1997) 'Resisting 'globalisation-from-above' through 'globalisationfrom-below", New Political Economy, 2: 1, $17-24$ Kesteloot, C. en Mistiaen, P. (1997) From ethnic niche to assimilation: Turkish restaurants in Brussels, Area, 29, 4, p.325-334

Li, W. en Teixeira, C. (2007) Introduction: immigrants and transnational experiences in world cities, GeoJournal, 68, pp. 93-102

Tarrius, A. en Missaoui, L. (1995), Les Arabes de France dans l'économie mondiale souterraine. La Tour d'Aigues: Ed. de l'Aube

Tarrius, A. (2002) La mondialisation par le bas. Paris: Balland 